\title{
CASA MUSEO
}

Soledad Alonso Portillo

Germán Alvarez de Pedro

J. Antonio Aranda Rosel

Facundo Caballero Ciudad

Manuel Cabezas Gómez del Campo

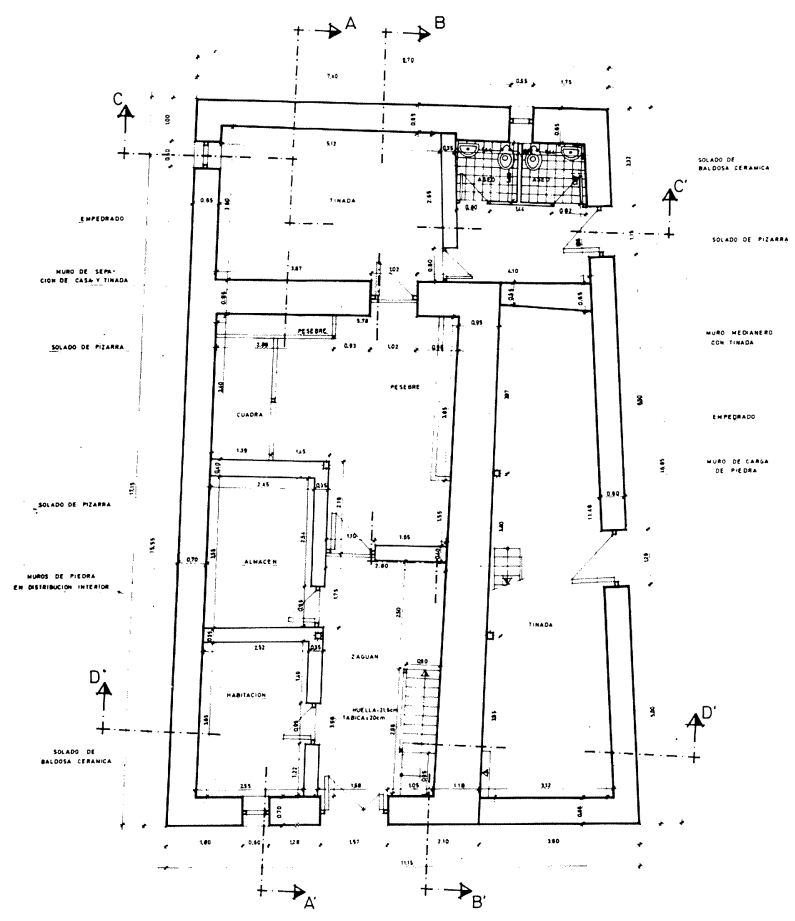

Planta baja (reformada)

\section{Situación}

El edificio está situado al noroeste del pueblo, cerca de la iglesia y de la manzana que se propone rehabilitar, dentro de la primera fase.

\section{Descripción del edificio en su estado actual}

El edificio consta de casa y tres tinadas adosadas alrededor de la vivienda formando una «ele». Su fachada principal, orientada al sur, es la mejor cuidada y cuenta con tres huecos de ventana y la puerta principal. La cubierta está resuelta a dos aguas con dos partes algo diferenciadas, una más elevada perteneciente a la vivienda, y otra de menor altura que cubre las tinadas.

La casa interiormente consta de tres plantas. La planta baja está formada por el zaguán, habitación, almacén, cuadra y acceso a la tinada norte. Por la escalera de un sólo tramo se comunica con la primera planta que consta de salón, alcoba, cocina, dos habitaciones y escalera (actualmente inexistente) de acceso a planta de sobrado.

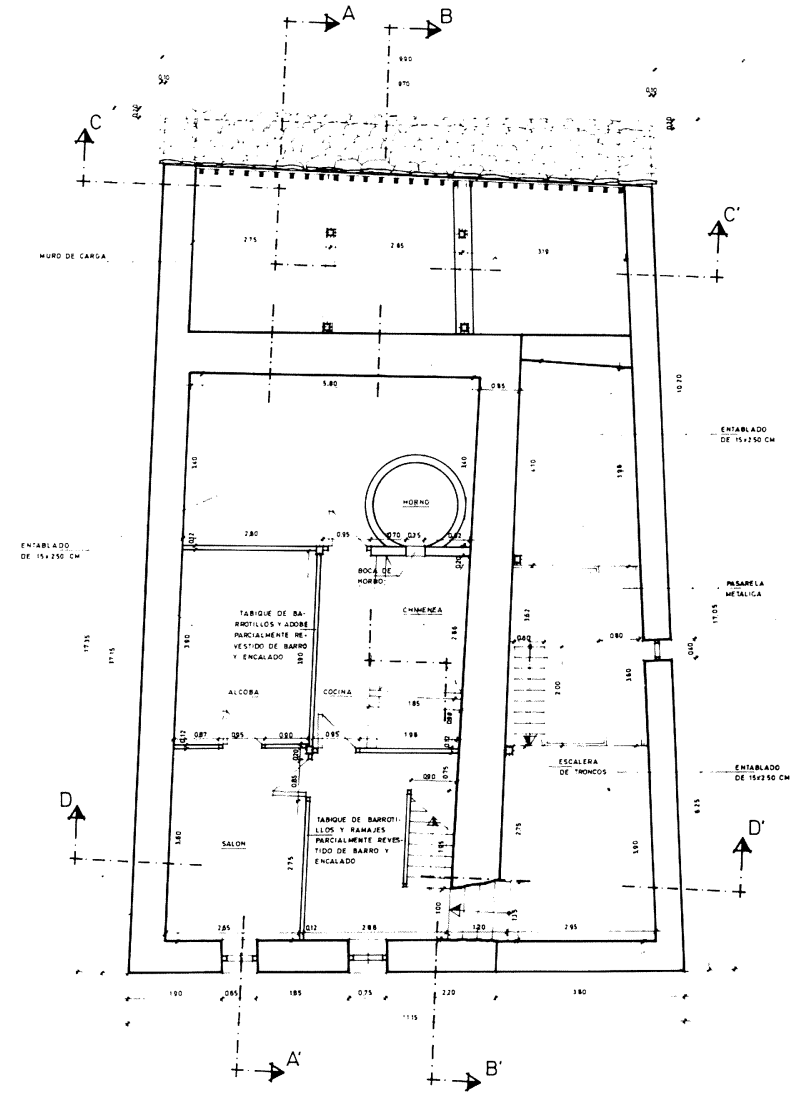

Planta primera (reformada)

Esta planta es diáfana, con algunos tabiques de mediana altura para almacenaje de grano.

Las tinadas están destinadas a cuadras y almacenes; cada tinada tiene restos de entreplantas, que definen espacios también utilizables.

La estructura de la vivienda responde al tipo de dos crujías, cambiando la dirección de los forjados en cada planta. Dispone de una fila de dos pies derechos que arrancan desde la cimentación y llegan hasta la cubierta, y de tres vigas, dos en techo de planta baja paralelas a fachada y una en techo de planta primera y perpendicular a las dos anteriores. Los forjados son de viguetas de madera de roble y se hallan en muy mal estado.

La estructura de la cubierta se compone de correas paralelas a fachada que apoyan en los muros, en los pies derechos y en enanos.

Los muros exteriores son de mampostería recibida con mortero de barro y paja, no presentando desplomes notables. 


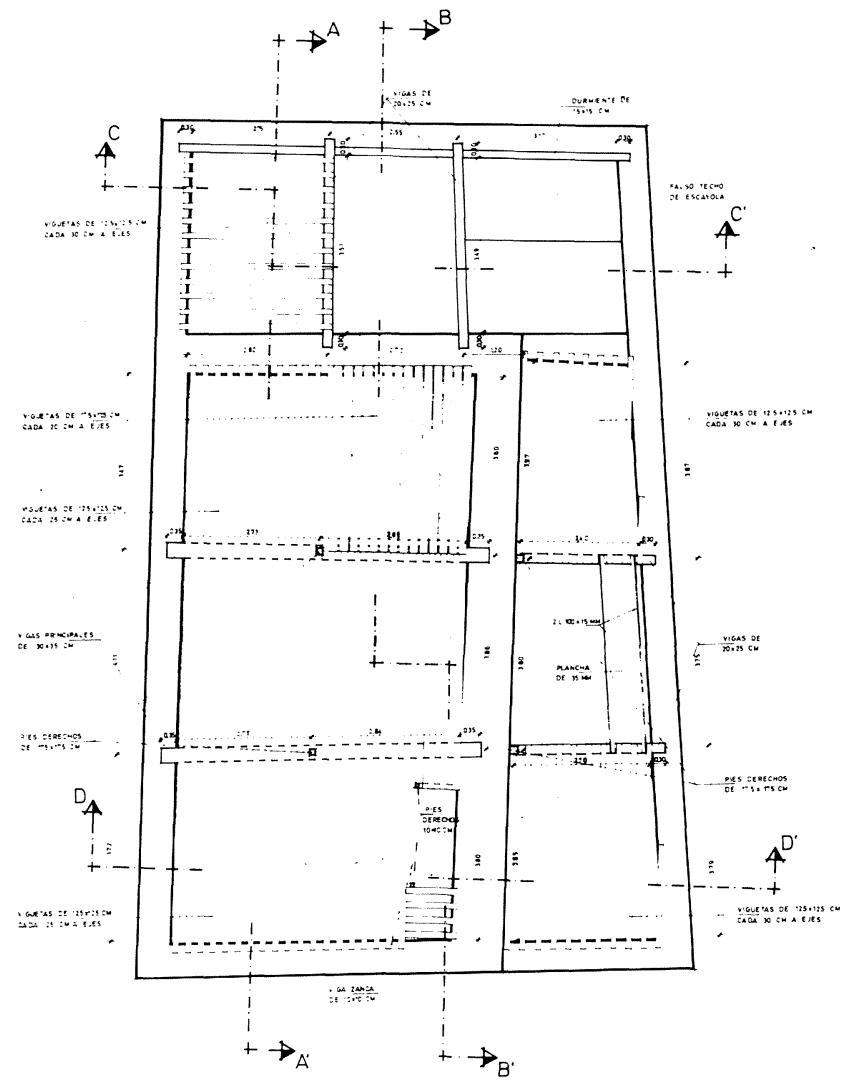

Estructura de suelo planta primera

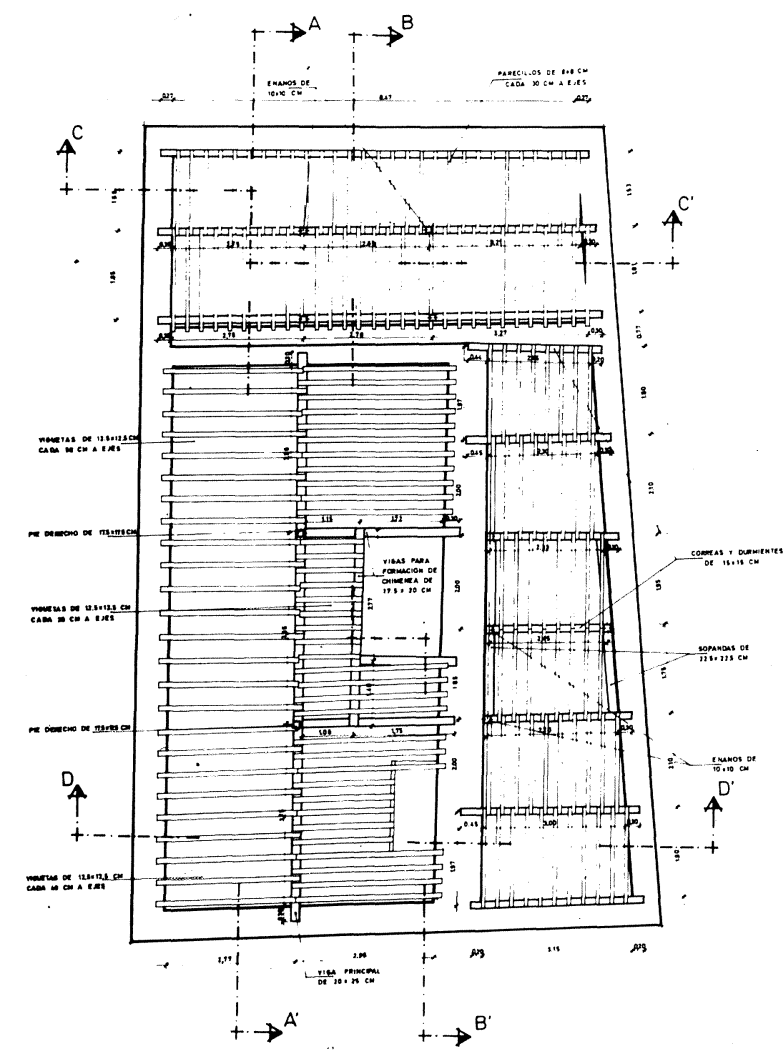

Estructura de techo planta primera

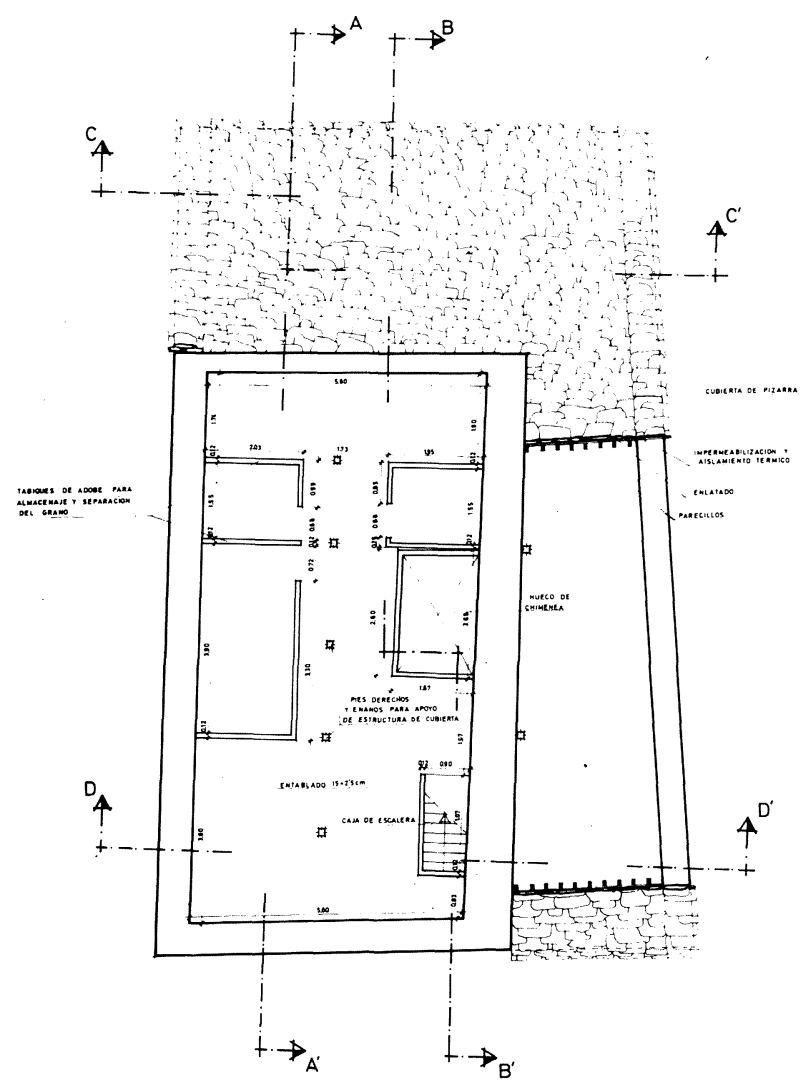

Planta de sobrado (reformada)

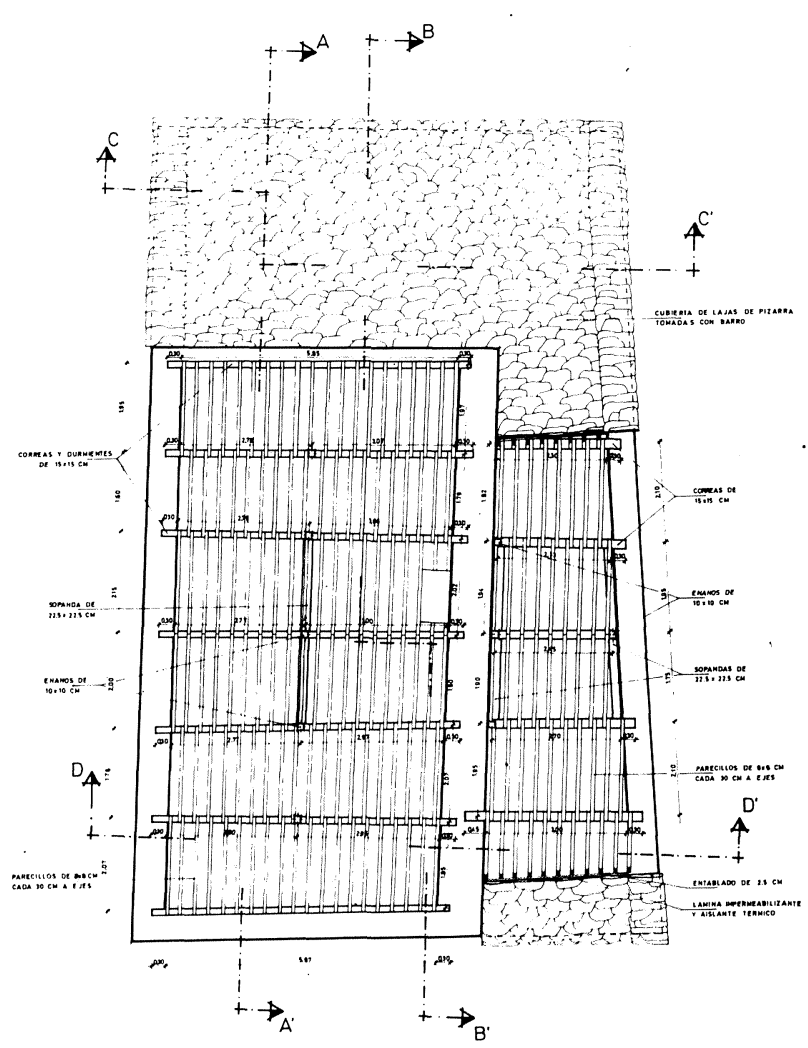

Estructura de cubierta 


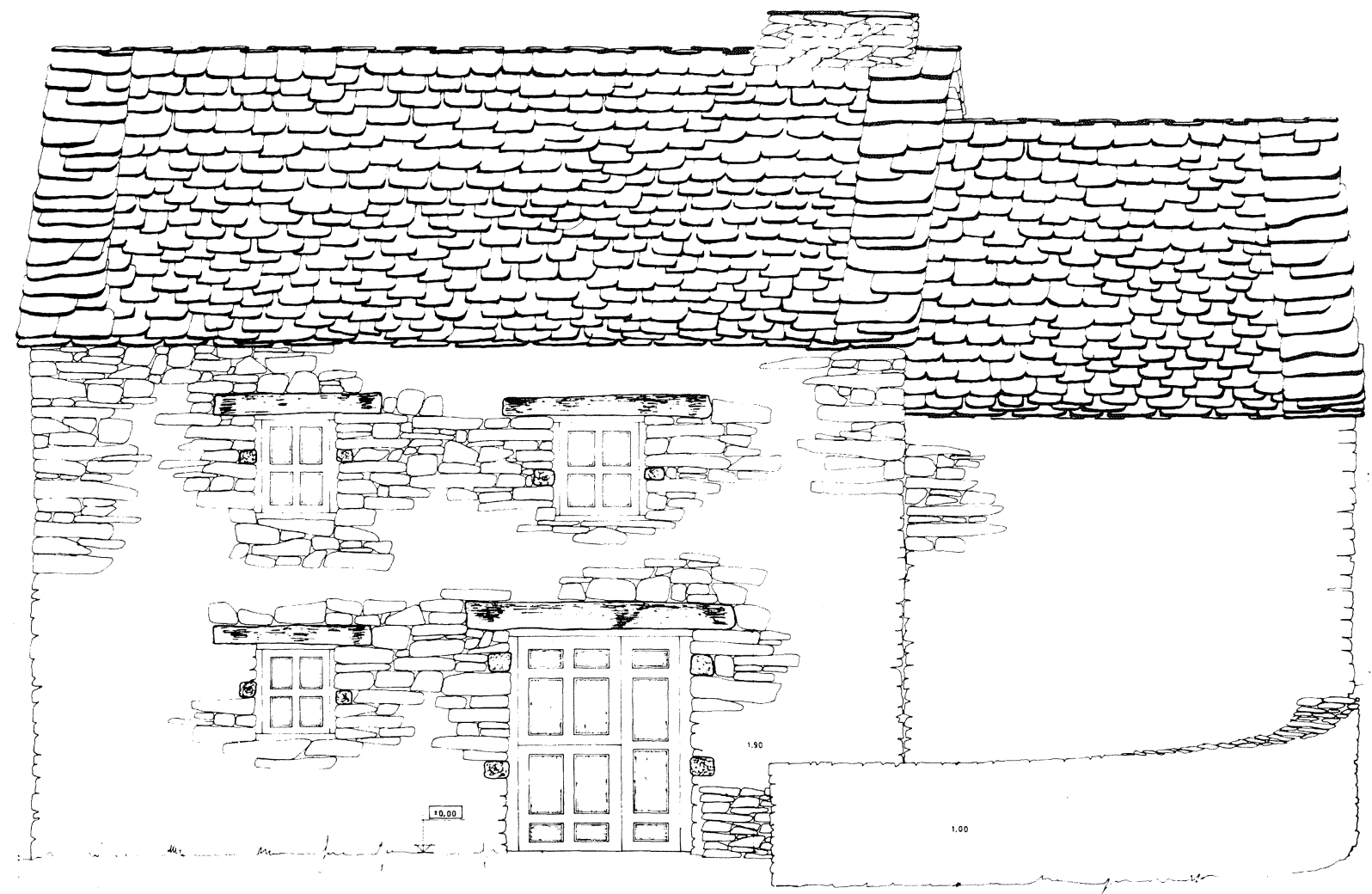

\section{Alzado principal (reformado)}

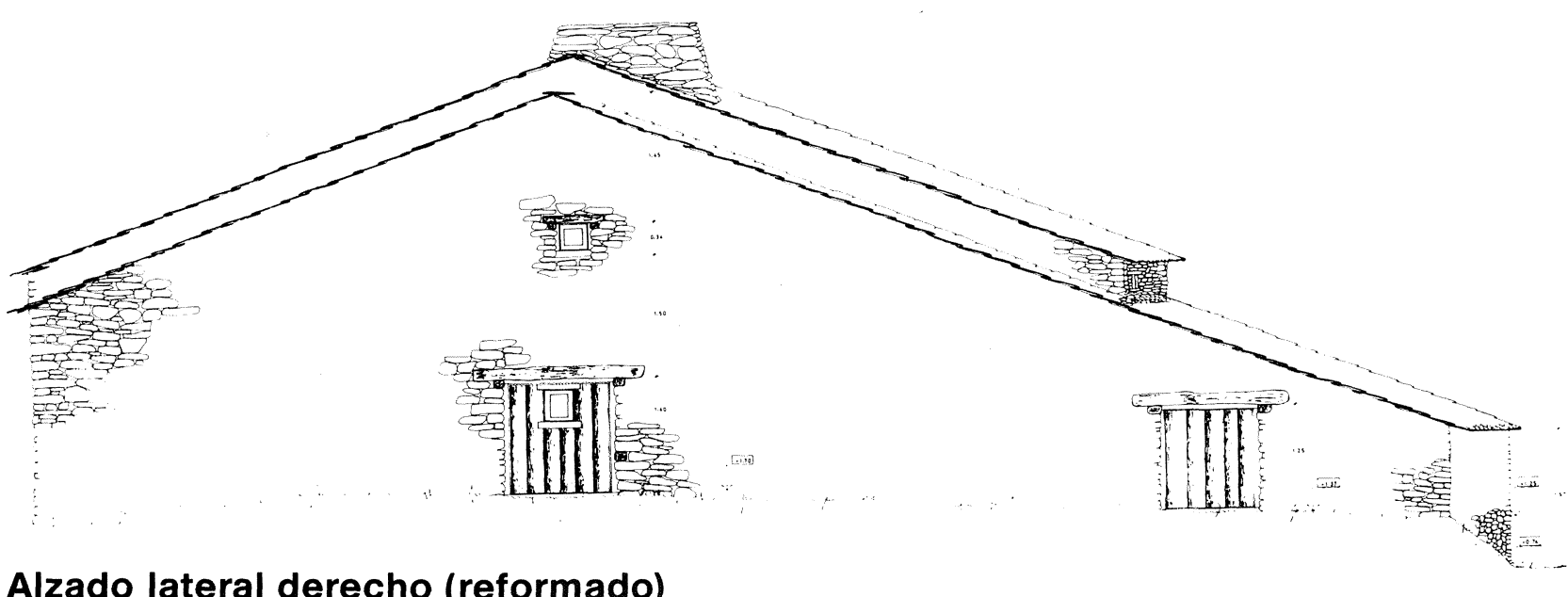

\section{Alzado lateral derecho (reformado)}

La tabiquería, cubierta y acabados, están resueltos según las técnicas y materiales empleados en el resto de los edificios del pueblo, presentando algunas reformas posteriores y utilizando otros materiales como ladrillos cerámicos huecos en tabiquería y teja curva en cubierta.

\section{Nuevo uso}

Debido a que el edificio responde a las caracteristicas de tipología genérica del pueblo y a la necesidad de un lugar donde exponer el mobiliario, los utensilios y la artesania original, se propone destinar el edificio a museo, donde se podrán mostrar las técnicas constructivas utilizadas en la arquitectura popular y los muebles antes mencionados.

Por ello, más que una rehabilitación, se propone hacer una reconstrucción del edificio según su estado primitivo y con las mismas técnicas y materiales originales, de forma que cuando se visite se pueda hacer una lectura de sus sistemas constructivos.

La distribución adoptada es la original de la casa, dotándola además de una zona de servicios para el público localizados en la tinada posterior y practicando un hueco 

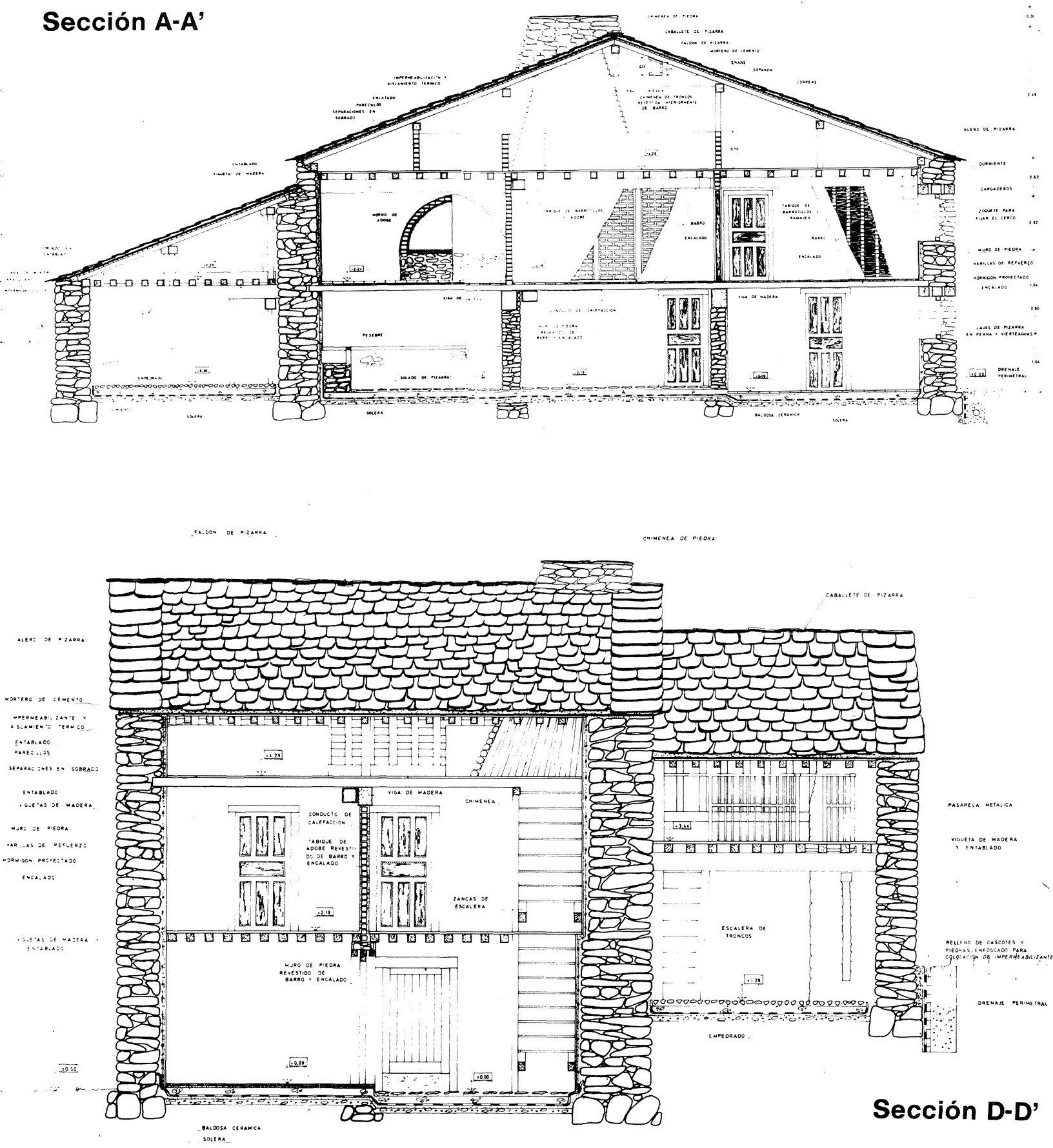

en el muro que separa la vivienda de la tinada lateral para permitir realizar el recorrido. Para ello se instala una pasarela metálica que comunica las entreplantas de la tinada.

\section{Solución constructiva}

Se ha procurado establecer una clara diferencia entre los nuevos materiales empleados (pasarela metálica, conducciones de calefacción, etc.) y los antiguos, exagerando los primeros para hacer ver en todo momento que son posteriores.
Para refuerzo de los muros de cerramiento se colocará un mallazo con redondos de $8 \mathrm{~mm}$ de diámetro, colocados en retícula cada $20 \mathrm{~cm}$. Sobre este mallazo se proyectará un hormigón de $175 \mathrm{~kg} / \mathrm{cm}^{2}$ de resistencia característica, con un espesor medio de $5 \mathrm{~cm}$.

La estructura se tendrá que realizar de nuevo con madera de roble, aprovechando la del derribo y completando con las piezas almacenadas en el pueblo. Esta madera deberá ser cortada y preparada para obtener las dimensiones y formas adecuadas.

Antes de levantar la estructura será necesario realizar un 
cajeado en el terreno para la posterior colocación de encachado, impermeabilización y solera de hormigón, todo ello con espesores reducidos por ser el suelo rocoso y laborioso de excavar.

La cubierta es a dos aguas, con una pendiente aproximada de $30^{\circ}$, realizada con entablado de madera, lámina impermeabilizante, aislamiento de planchas de poliestireno extrusionado y capa de mortero de cemento sobre la que asientan las lajas de pizarra.

En algunas zonas la tabiquería interior se ejecutará según las tres técnicas originales de barrotillos y adobe, de barrotillos y ramajes entrelazados, y de muros de piedra (en planta baja), de forma que puedan ser observadas por el visitante.

El horno y la chimenea tendrán las mismas caracteristicas que las originales, siendo el horno circular de $1,00 \mathrm{~m}$ de diámetro y $1,60 \mathrm{~m}$ de altura, formado con base de piedra y cúpula elíptica de adobe revestido con barro. La chimenea con gran campana que ocupa gran parte de la cocina forma una pirámide truncada de base rectangular.

Los revestimientos se realizarán de barro mezclado con paja y pintados con cal.

$$
\text { is 论猔 }
$$

\section{publicaciones del I.E.T.c.c.}

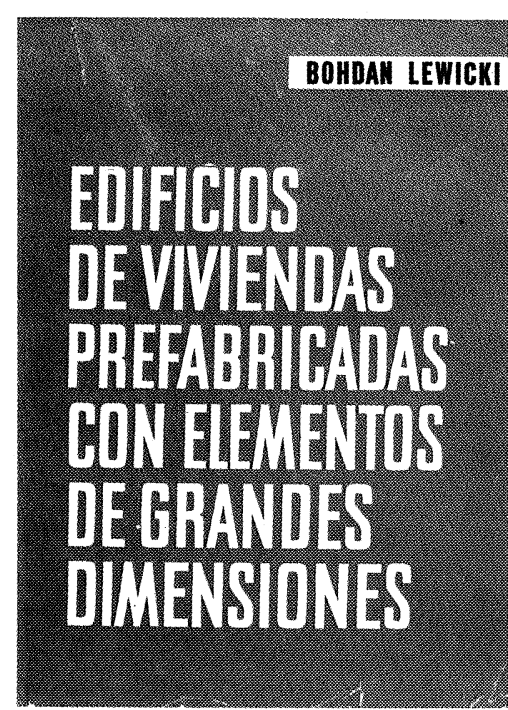

Bohdan Lewicki

Este libro trata de los problemas relativos a la construcción de los edificios de viviendas o publicos realizados con elementos prefabricados de grandes dimensiones. Se han estudiado los problemas de arriostramiento, asi como los que plantea la resistencia de los elementos y de la estructura; se han examinado las cuestiones de orden higrotérmico, acústico y de resistencia al fuego: también se ha profundizado en el estudio de la estanquidad de los muros exteriores y de las juntas.

La obra incluye numerosas ilustraciones que dan detalles de diversas soluciones, as como ejemplos de cálculo, tablas de valores numéricos, diagramas y ábacos.

Un volumen encuadernado en tela, de $24 \times 17 \mathrm{~cm}$, compuesto de 616 págs.

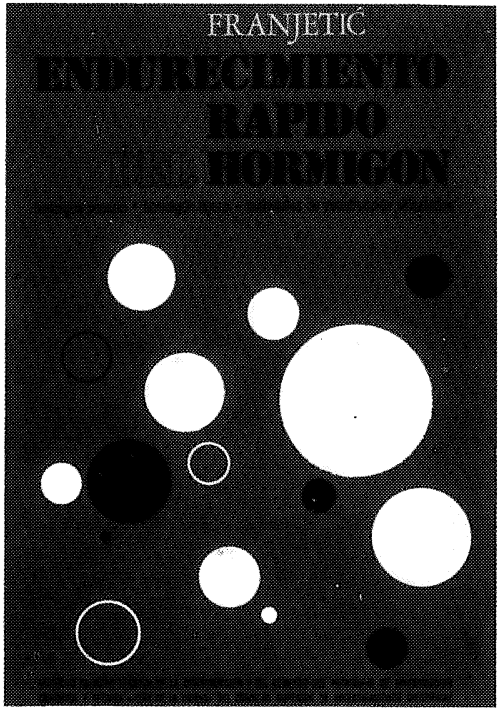

Zorislav Franjetić

En la obra de Franjetić se expone de una forma minuciosa, ordenada y sistemática todo un cuerpo de doctrina que reúne el cotodo un cuerpo de doctrina que reúne el corápido del hormigón. Parte el autor de los principios básicos y llega a las últimas consecuencias y realidades técnicas y economicas.

Es una obra de consulta, tanto para el investigador sobre la materia, como para proyectista y el realizador y montador de plantas e instalaciones y equipos de curado y endurecimiento rápido.

Un volumen encuadernado en cartoné, de $17 \times 24,5 \mathrm{~cm}$, compuesto de 385 págs. 110 figuras y 10 tablas.

Precios: 2.500 ptas.; \$USA 36.00

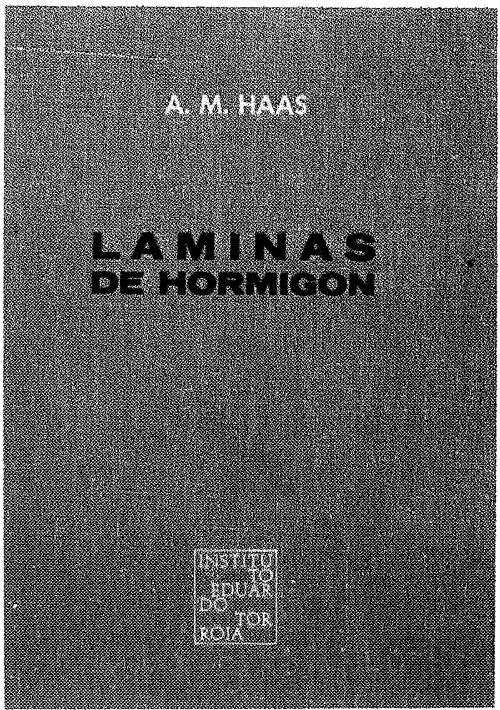

\section{A. M. Haas}

Al escribir este libro el autor intento poner a disposición de los estudiantes y de los ingenieros unos conocimientos prácticos, adecuados para servir de guía en el diseño y construcción de láminas delgadas de hormigón.

El autor está convencido de que el éxito en el diseño de una lámina exige por parte del proyectista, un examen de las tres fases por proyectista, un examen de las tres fases por el diseño, el análisis estructural y la construcción de la estructura.

Un volumen encuadernado en tela de $17 \times 24,5 \mathrm{~cm}$, compuesto de 420 págs., 141 figuras, 22 fotografias y 6 tablas.

Precios: 2.500 ptas.; \$USA 36.00 .

Precios: 2.500 ptas.; \$USA 36.00 . 